\title{
Potentiation of Tubuloglomerular Feedback in the Rat by Thromboxane Mimetic Role of Macula Densa
}

\author{
W. J. Welch and C. S. Wilcox
}

Divisions of Nephrology, Hypertension, and Transplantation, Departments of Medicine, Pharmacology, and Therapeutics, College of Medicine, University of Florida, and Department of Veterans Affairs Medical Center, Gainesville, Florida 32602

\begin{abstract}
Because endogenous thromboxane $\mathrm{A}_{2}\left(\mathrm{TXA}_{2}\right)$ potentiates the tubuloglomerular feedback response (TGF), we studied the mechanism of action of TXA $\mathbf{A}_{2}$ by using a stable $T X \mathbf{A}_{2} /$ prostaglandin (PG) $\mathrm{H}_{2}$ mimetic, $U-46,619$. Intravenous infusion of $\mathrm{U}-46,619$ at $100 \mathrm{ng} \cdot \mathrm{kg}^{-1} \cdot \mathrm{min}^{-1}$ reduced the GFR and the single-nephron (SN)GFR measured from the distal tubule (macula densa function intact), whereas the SNGFR measured from the proximal tubule (macula densa function interrupted) was not changed consistently. 10-100-fold higher rates of infusion of $U-46,619$ were required to raise blood pressure or femoral vascular resistance. The regulation of glomerular capillary pressure $\left(P_{G C}\right)$ by TGF was assessed in anesthetized rats from changes in proximal stop flow pressure (PSF) and/or SNGFR during perfusion of the loop of Henle (LH) with artificial tubular fluid (ATF). Orthograde loop perfusion and retrograde perfusion of $U-46,619$ into the macula densa segment reduced PSF. Responses to luminal U-46,619 were blunted by a $\mathrm{TXA}_{2}-$ $\mathbf{P G H}_{2}$ receptor antagonist. Orthograde loop perfusions with luminal $\mathrm{U}-\mathbf{4 6 , 6 1 9}$ increased net $\mathrm{Cl}$ absorption, whereas coperfusion with furosemide $\left(10^{-4} \mathrm{M}\right)$ blunted the response to $\mathrm{U}-46,619$ by $68 \%$. These data indicated that the luminal U-46,619 might increase the signal for TGF activation by increasing $\mathrm{Cl}$ reabsorption in macula densa cells. However, since $80 \pm 4 \%$ of $\left[{ }^{3} \mathrm{H}\right] \mathrm{U}-46,619$ perfused via the $\mathrm{LH}$ was reabsorbed, peritubular capillaries (PTC) were perfused with $U-46,619$ to test additional extra-luminal actions. PTC perfusion with U-46,619 again increased TGF by reducing PSF selectively only while macula densa function was intact during perfusion of the LH with ATF. Conclusions: (a) TGF is potentiated by U-46,619 given systemically, via the lumen of the $\mathrm{LH}$ by orthograde or retrograde perfusions or via the PTC; $(b)$ at the lower doses tested, reduction of $P_{G C}$ and SNGFR by $U-46,619$ depends on tubular fluid delivery and reabsorption by the macula densa; (c) potentiation of TGF by $U-46,619$ entails preglomerular vasoconstriction which may be elicited in part by an increased signal due to increased net chloride reabsorption in the LH and presumably macula densa cells and by an increased
\end{abstract}

Parts of this report were presented in abstract form to the American Society of Nephrology (1989. Kidney Int. 37:602) and the Federation of American Societies for Experimental Biology (1990. FASEB J. 4:A1077).

Address reprint requests to Dr. Welch, Division of Nephrology, University of Florida, Box J-224, JHMHC, Gainesville, FL 32602.

Received for publication 26 December 1991 and in revised form 2 January 1992.

J. Clin. Invest.

(c) The American Society for Clinical Investigation, Inc.

$0021-9738 / 92 / 06 / 1857 / 09 \$ 2.00$

Volume 89, June 1992, 1857-1865 sensitivity of the arteriole to macula densa-derived signals; $(d)$ activation of TGF may contribute to the selective vasoconstriction of the renal vascular bed by low doses of $U-46,619$. ( $J$. Clin. Invest. 1992. 89:1857-1865.) Key words: macula densa • thromboxane $A_{2} \cdot$ tubuloglomerular feedback $\bullet U-46,619$

\section{Introduction}

Tubuloglomerular feedback (TGF) ${ }^{1}$ is a vasoconstrictive response that reduces the glomerular capillary pressure $\left(P_{G C}\right)$ and the single-nephron glomerular filtration rate (SNGFR) and limits $\mathrm{NaCl}$ excretion. It depends upon delivery and reabsorption of $\mathrm{NaCl}$ in the macula densa segment of the loop of Henle (LH) $(1,2)$. Adenosine $(3)$ and angiotensin II $(4,5)$ have been implicated in the preglomerular vasoconstriction. Using a wholekidney model of TGF entailing intrarenal infusion of hypertonic $\mathrm{NaCl}$, we demonstrated increased release of the thromboxane $\mathrm{A}_{2}$ (TXA $\mathrm{TX}_{2}$ ) metabolite $\mathrm{TXB}_{2}$ into renal lymph and urine (6) and blunting of the pre- and postglomerular vasoconstriction by a $\mathrm{TXA}_{2}$ synthesis inhibitor (7). Thereafter, in single-nephron studies, inhibition of endogenous $\mathrm{TXA}_{2}$ synthesis or TXA $A_{2}$ prostaglandin (PG) $\mathrm{H}_{2}$ receptors was found to blunt the fall in SNGFR and $P_{G C}$ during orthograde perfusion of the LH (8) by an angiotensin-independent mechanism (5). The aim of the present study was to investigate the mechanisms whereby $\mathrm{TXA}_{2}$ potentiates TGF-induced changes in $\mathrm{P}_{\mathrm{GC}}$ using a stable $\mathrm{TXA}_{2} / \mathrm{PGH}_{2}$ mimetic U-46,619 (9).

The hierarchy of responses to intravenous $U-46,619$ was assessed from dose-response relationships for TGF-induced changes in $\mathrm{P}_{\mathrm{GC}}$, SNGFR, renal and femoral hemodynamics, and blood pressure (BP). The role of $\mathrm{TXA}_{2} / \mathrm{PGH}_{2}$ receptors was assessed using the specific, competitive receptor antagonist, SQ-29,548 (10). Because TXB $_{2}$ has been detected recently in proximal tubule fluid $(11,12)$, we tested the effects of U-46,619 delivered via the lumen of the perfused loop of Henle (LH) on the TGF response. The role of the macula densa in the response to $U-46,619$ was assessed by retrograde infusion of $\mathrm{U}-46,619$ from the distal tubule into the macula densa segment and from a comparison of the effects of intravenous U-46,619 on SNGFR measured from the proximal and distal tubules.

1. Abbreviations used in this paper: APF, artificial plasma fluid; ATF, artificial tubular fluid; BP, blood pressure; [ED ${ }_{\mathrm{a}}$ ], early distal tubular fluid chloride concentration; FBF, femoral blood flow; FVR, femoral vascular resistance; $\mathrm{J}_{\mathrm{C}}$, net chloride reabsorption; $\mathrm{LH}$, loop of Henle, $\mathrm{MBP}$, mean BP, $\mathrm{P}_{\mathrm{GC}}$, glomerular capillary pressure; PSF, proximal stop flow pressure; PTC, peritubular capillary; RBF, renal blood flow; RPF, renal plasma flow; RVR, renal vascular resistance; SNGFR, single-nephron glomerular filtration rate; $\mathrm{TF}_{\mathrm{v}}$, tubular fluid flow rate; TGF, tubuloglomerular feedback (response); UV, urine flow rate; $U_{\mathrm{Na}} V, U_{K} V$, or $U_{\mathrm{Cl}} V$, renal excretion of sodium, potassium, or chloride.

Thromboxane Mimetic and Tubuloglomerular Feedback

1857 
During proximal tubule fluid collection, the delivery of tubular fluid to the macula densa segment is interrupted while during distal tubule collection it is intact (13). Recently macula densa cells have been shown to resemble thick ascending $\mathrm{LH}$ cells in possessing a furosemide-sensitive apical $\mathrm{Na} / \mathrm{K} / 2 \mathrm{Cl}$ cotransport step (14). Therefore, further studies were undertaken to assess the effect of $U-46,619$ on the signal generated by reabsorption of $\mathrm{NaCl}$ by the macula densa cells, or the response of the arteriole to this signal. This was studied from the effects of luminal perfusion of the $\mathrm{Na} / \mathrm{K} / 2 \mathrm{Cl}$ cotransport inhibitor, furosemide, on TGF responses to graded doses of luminal U-46,619 and from measurement of net $\mathrm{Cl}$ reabsorption $\left(\mathrm{J}_{\mathrm{Cl}}\right)$ in the $\mathrm{LH}$ during perfusion with U-46,619. To determine whether U-46,619 could engage TGF via an extraluminal action, the drug was infused directly into the peritubular capillaries while TGF was assessed from changes in PSF during graded perfusion of the LH of the target nephron with artificial tubular fluid.

\section{Methods}

Animal preparation. Male Sprague-Dawley rats (211-254 g) were maintained on rat chow (rodent laboratory Chow 5001; Ralston Purina Co., St. Louis, MO) and surgically prepared for in vivo micropuncture as previously described in detail (8). Albumin $\left(3 \mathrm{~g} \cdot \mathrm{dl}^{-1}\right.$; Sigma Chemical Co., St. Louis, MO) was dissolved in $0.15 \mathrm{M} \mathrm{NaCl}$ and infused throughout at $0.5 \mathrm{ml} \cdot 100 \mathrm{~g}$ body weight ${ }^{-1} \cdot \mathrm{h}^{-1}$ after a priming dose of $0.5 \mathrm{ml}$ to maintain a euvolemic state. $\left[{ }^{3} \mathrm{H}\right]$ inulin $\left(0.1 \mu \mathrm{Ci} \cdot \mathrm{kg}^{-1} \cdot \mathrm{h}^{-1}\right)$ and $\left[{ }^{14} \mathrm{C}\right]$ paraaminohippurate $\left(0.05 \mu \mathrm{Ci} \cdot \mathrm{kg}^{-1} \cdot \mathrm{h}^{-1}\right.$, both supplied by New England Nuclear, Boston, MA) were added to this infusion to measure GFR and renal plasma flow (RPF), respectively. $\left[{ }^{3} \mathrm{H}\right]$ Inulin was infused at a dose of $0.5 \mu \mathrm{Ci} \cdot \mathrm{kg}^{-1} \cdot \mathrm{h}^{-1}$ for measurement of SNGFR. Renal extraction of PAH was not assessed; previous studies had shown that alteration in endogenous $\mathrm{TXA}_{2}$ generation did not alter renal paraaminohippurate extraction in the rat (7). Renal vascular resistance (RVR) was calculated from mean BP (MBP) factored by renal blood flow (RBF).

Individual nephrons were identified by insertion of a localizing pipette (4-6 $\mu \mathrm{m}, 0 . d$.) and injection of a small volume $(10-20 \mathrm{nl})$ of artificial tubular fluid (ATF), which had a composition similar to endproximal tubule fluid (5) and was stained with fast-green ( $1 \% \mathrm{~F}, \mathrm{D}$ and C, Sigma Chemical Co.). The last loop of the proximal tubule was punctured with a perfusion pipette $(7-10 \mu \mathrm{m}$, o.d.) connected to a variable nanoliter perfusion pump (World Precision Instruments, Inc., New Haven, CT). An immobile wax block was placed in the proximal tubule upstream from the perfusion pipette using a hydraulic syringe (Trent Wells, San Diego, CA). A pressure pipette $(1-2 \mu \mathrm{m}$, o.d.) connected to a servonull pressure measuring device (IPM, Inc., La Jolla, CA) was inserted into the proximal tubule upstream from the wax block to measure the proximal stop flow pressure (PSF). PSF defines the net filtering pressure at the glomerulus; in the absence of a change in plasma oncotic pressure, $\mathrm{PSF}$ is proportional to $\mathrm{P}_{\mathrm{GC}}$. The changes in PSF during graded alterations in the rate of flow of ATF into the LH from 0 to $40 \mathrm{nl} \cdot \mathrm{min}^{-1}$ were used to characterize the TGF response. There is normally a sigmoidal relationship between PSF and LH perfusion. The set point for the TGF response was taken as the value of PSF during zero $\mathrm{LH}$ perfusion. The overall response was taken as the change in PSF between 0 and $40 \mathrm{nl} \cdot \mathrm{min}^{-1}$ of LH perfusion. The turning point was assessed using a curve-fitting program as the rate of $\mathrm{LH}$ perfusion corresponding to a 50\% change in PSF. In some studies, the TGF response was assessed from changes in SNGFR; for one set of studies, timed collections of proximal tubule fluid were made during perfusion of the $\mathrm{LH}$ with ATF at 0 and $40 \mathrm{nl} \cdot \mathrm{min}^{-1}$. For another set, free-flow micropuncture samples were drawn from the proximal and distal tubules upstream from a mobile oil droplet. Tubular fluid volumes were measured in a calibrated, constant-bore micropipette and tubular fluid flow rate $\left(\mathrm{TF}_{\mathrm{v}}\right)$ was calculated. SNGFR was taken as the product of $\mathrm{TF}_{\mathrm{v}}$ and the tubular fluid/plasma ratio for ${ }^{3} \mathrm{H}$ activity.

After completion of surgery, there was a 30 -min equilibration period. For the first series, this was followed by a basal period of $90 \mathrm{~min}$ (period 1) during which clearance and micropuncture measurements were made. Thereafter, test solutions or vehicle were infused and, after $5 \mathrm{~min}$, there was an experimental period of $90 \mathrm{~min}($ period 2) when clearance and micropuncture measurements were repeated. Blood was sampled at the midpoints. This protocol followed exactly previous series $(5,8)$ where it was shown that, if no drugs were given during period 2 , there were no changes between periods 1 and 2 in MBP, GFR, RPF, urine flow rate (UV), renal excretion of sodium $\left(\mathrm{U}_{\mathrm{Na}} \mathrm{V}\right)$, potassium $\left(\mathrm{U}_{\mathrm{K}} \mathrm{V}\right)$, chloride $\left(\mathrm{U}_{\mathrm{C}} \mathrm{V}\right)$, prostacyclin $\left(\mathrm{PGI}_{2}\right)$ metabolite $\left(\mathrm{U}_{6 \mathbf{k G F l \alpha}} \mathrm{V}\right)$, or $\mathrm{TXA}_{2}$ metabolite $\left(\mathrm{U}_{\mathrm{TXB} 2} \mathrm{~V}\right)$. Moreover, TGF responses, whether assessed from changes in PSF or SNGFR also remained stable.

Protocols. The aim of the first protocol was to test the hypothesis that there was a differential sensitivity of renal and systemic hemodynamic responses to infused U-46,619 that could be ascribed to activation of TGF. Studies were undertaken to contrast the dose-response relationships for intravenous U-46,619 on TGF-mediated changes in PSF or SNGFR, MBP, and renal and femoral hemodynamics. Femoral blood flow (FBF) was assessed with a noncannulating electromagnetic flow probe connected to a blood flow meter (Carolina Medical Electronics, King, NC). Femoral vascular resistance (FVR) was calculated from MBP factored by FBF. For this series, U-46,619 was infused i.v. at $1,10,100,1,000$, or $10,000 \mathrm{ng} \cdot \mathrm{kg}^{-1} \cdot \mathrm{min}^{-1}$ during period 2 . Each rat received only one dose of $U-46,619$. The complete TGF response for changes in PSF during perfusion of the LH with ATF at $0,10,20,30$, and $40 \mathrm{nl} \cdot \mathrm{min}^{-1}$ was assessed during the basal period and during the infusions of U-46,619 at the three lower doses. To determine the role of TGF in reducing glomerular filtration with U-46,619, free-flow measurements of SNGFR were contrasted for samples drawn from the proximal and distal tubules before (period 1) and during (period 2) intravenous infusion of $\mathrm{U}-46,619$ at 10 and $100 \mathrm{ng} \cdot \mathrm{kg}^{-1} \cdot \mathrm{min}^{-1}$.

The aim of the second protocol was to test the hypothesis that $\mathrm{U}-46,619$ could engage TGF via a luminal route. The $\mathrm{TXA}_{2} / \mathrm{PGH}_{2}$ mimetic was given directly into the lumen of the $\mathrm{LH}$ by addition to ATF perfusing the test nephron. The TGF response was measured from changes in PSF between 0 and $40 \mathrm{nl} \cdot \mathrm{min}^{-1}$ of $\mathrm{LH}$ perfusion. Each paired observation was made as a continuous recording of PSF during a control perfusion of ATF + vehicle followed by replacement of the perfusion pipette with one containing ATF + U-46,619 or vice versa. In some nephrons, it was possible to return to the original perfusion solution and, in these instances, a very comparable TGF response was seen between the basal and postcontrol perfusions. One or two paired recordings were made in each rat. TGF was also assessed from changes in SNGFR during perfusion of the LH at 0 and $40 \mathrm{nl} \cdot \mathrm{min}^{-1}$ with ATF + vehicle and contrasted with ATF + U-46,619 $\left(10^{-6} \mathrm{M}\right)$.

The aim of the third protocol was to test the hypothesis that the effect of luminal U-46,619 on TGF was mediated by specific $\mathrm{TXA}_{2} /$ $\mathrm{PGH}_{2}$ receptors, using the $\mathrm{TXA}_{2} / \mathrm{PGH}_{2}$ receptor antagonist $\mathrm{SQ}-29,548$ (10). TGF was assessed from measurements of SNGFR during perfusion of the LH with ATF at 0 and $40 \mathrm{nl} \cdot \mathrm{min}^{-1}$ (order randomized), as described above. The effects of perfusion of the LH with U-46,619 $\left(10^{-6} \mathrm{M}\right)$ added to ATF at $40 \mathrm{nl} \cdot \mathrm{min}^{-1}$ were assessed in two groups of nephrons. Each nephron $(n=7)$ was perfused with ATF + vehicle, ATF + U-46,619, and ATF + SQ-29,548 + U-46,619.

The aim of the fourth protocol was to test the hypothesis that U-46,619 could engage TGF by a direct action on the macula densa segment. The proximal tubule near the last surface convolution was identified, a wax block was placed, and the tubule was vented downstream to ensure escape of the perfusate. PSF was measured while the distal tubule was perfused retrogradely into the $\mathrm{LH}$ with $\mathrm{ATF}+$ vehicle or ATF + U-46,619 $\left(10^{-5} \mathrm{M}\right)$ at $10 \mathrm{nl} \cdot \mathrm{min}^{-1}$.

The aim of the fifth protocol was to test the hypothesis that luminal U-46,619 could engage TGF by enhancing the signal generated by $\mathrm{Cl}$ reabsorption at the macula densa segment $(2,13,14)$. Because this 
could not be measured directly, it was assessed from the effects of luminal furosemide $\left(10^{-4} \mathrm{M}\right)$ on U-46,619-induced changes in PSF; furosemide blocks the entry step for $\mathrm{Na} / \mathrm{K} / 2 \mathrm{Cl}$ absorption by both thick ascending limb and macula densa cells (14). In addition, the effects of $\mathrm{U}-46,619$ on $\mathrm{J}_{\mathrm{a}}$ in the perfused $\mathrm{LH}$ were assessed directly. TGF responses were measured from changes in PSF in two to four separate nephrons of each rat during 0 and $40 \mathrm{nl} \cdot \mathrm{min}^{-1}$ perfusion of ATF via the LH. Perfusates contained either ATF + vehicle or ATF + furosemide $\left(10^{-4} \mathrm{M}\right)$ or ATF $+\mathrm{U}-46,619\left(10^{-8}\right.$ to $\left.10^{-4} \mathrm{M}\right)$ or ATF + U-46,619 $\left(10^{-6}\right.$ or $\left.10^{-4} \mathrm{M}\right)+$ furosemide $\left(10^{-4} \mathrm{M}\right)$. The effect of luminal $U-46,619\left(10^{-6} M\right)$ on $J_{G}$ was assessed in eight nephrons while the $\mathrm{LH}$ was perfused from the late proximal tubule downstream from a wax block at $40 \mathrm{nl} \cdot \mathrm{min}^{-1}$ with an isotonic ATF solution (Cl concentration $142 \mathrm{mM}$ ) containing $\left[{ }^{3} \mathrm{H}\right]$ inulin as a recollection marker. Collected fluid was sampled from the first early distal convolution upstream from an oil block and analyzed for volume, $[\mathrm{Cl}]$, and ${ }^{3} \mathrm{H}$ activity. Measurements were made in the same nephron during perfusion of ATF + vehicle and compared to ATF + U-46,619 $\left(10^{-6} \mathrm{M}\right)$; the order was randomized between studies. Additional nephrons $(n=6)$ were studied during perfusions of the LH with ATF + vehicle or ATF + U$46,619\left(10^{-6} \mathrm{M}\right)$ at a lower rate of perfusion of $20 \mathrm{nl} \cdot \mathrm{min}^{-1}$. Finally, measurements were also made in eight nephrons during perfusion of the $\mathrm{LH}$ at $40 \mathrm{nl} \cdot \mathrm{min}^{-1}$ with ATF + furosemide $\left(10^{-4} \mathrm{M}\right)+$ vehicle and compared to ATF + furosemide $\left(10^{-4}\right)+\mathrm{U}-46,619\left(10^{-6} \mathrm{M}\right) . \mathrm{J}_{\mathrm{C}}$ was calculated from the difference between the rate of $\mathrm{Cl}$ delivery (the product of the perfusion rate from the calibrated nanoliter perfusion pump and the perfusate $[\mathrm{Cl}]$ ) and the rate of $\mathrm{Cl}$ collection (the product of the rate of fluid collection and the collectate fluid [Cl]).

The aim of the sixth protocol was to test the hypothesis that $\mathrm{U}-46,619$, perfused via the $\mathrm{LH}$ might be reabsorbed and therefore could act extraluminally. The reabsorption of $\left[{ }^{3} \mathrm{H}\right] \mathrm{U}-46,619$ was assessed in nine nephrons which were perfused with ATF at $20 \mathrm{nl} \cdot \mathrm{min}^{-1}$ to which was added $\left[{ }^{3} \mathrm{H}\right] \mathrm{U}-46,619\left(2 \mu \mathrm{Ci} \cdot \mathrm{ml}^{-1}\right.$; ICN Biochemicals, Indianapolis, IN); $\left[{ }^{14} \mathrm{C}\right]$ inulin was added to assess completeness of recollection. Net reabsorption was calculated as described above for $\mathrm{J}_{\mathrm{C}}$.

The aim of the seventh protocol was to test the hypothesis that U-46,619 could engage TGF responses via an extraluminal route. The TXA $2 / \mathrm{PGH}_{2}$ mimetic was delivered locally via the peritubular capillaries (PTC) while the LH of the experimental nephron was perfused with ATF at 0 or $40 \mathrm{nl} \cdot \mathrm{min}^{-1}$. A third pressure-sensing micropipette was placed upstream from a wax block in the proximal tubule of the test nephron to assess PSF. The PTC perfusion was delivered at 15 $\mathrm{nl} \cdot \mathrm{min}^{-1}$ via a micropipette (8-10 $\mu \mathrm{m}, 0 . d$.) inserted into an efferent arteriolar star vessel. The perfusate contained an artificial plasma fluid (APF) stained with $1 \% \mathrm{~F}, \mathrm{D}$ and $\mathrm{C}$ dye solution oxygenated with $95 \%$ $\mathrm{O}_{2}$ and $5 \% \mathrm{CO}_{2}$ as described by Mitchell and Navar (15). The rate of perfusion used was well below that which led to any apparent back-flux of perfusate down the efferent arteriole toward the glomerulus. Moreover, green dye did not appear in tubular fluid but escaped from the capillaries and stained the region surrounding the experimental nephron. Perfusion of some PTCs did not cause greening of the interstitium around the test nephron; these nephrons were not studied further. The TGF response was assessed by increasing the LH perfusion from 0 to $40 \mathrm{nl} \cdot \mathrm{min}^{-1}$ and back to 0 . It is not possible to withdraw the efferent arteriolar micropipette without inducing significant bleeding. Therefore, the TGF responses were assessed during PCT perfusion and compared to those obtained with the micropipette in place, but the perfusion not engaged. For the first control group $(n=6)$, the PTCs were perfused with APF + vehicle while for the second experiments group $(n=7)$ they were perfused with APF + U-46,619 $\left(10^{-6} \mathrm{M}\right)$.

Chemical methods. Samples of plasma, urine and tubular fluid were assessed for radioactivity in a liquid scintillation counter (Beckman Instruments, Inc., Palo Alto, $\mathrm{CA}$ ). $\mathrm{Na}$ and $\mathrm{K}$ concentrations were measured in a flame photometer (model 443, Instrumentation Laboratory, Inc., Lexington, MA). Urine $\mathrm{Cl}$ was measured in chloride meter (model 920 N, Corning Medical, Medfield, MA). Tubular fluid Cl concentrations were measured using silver electrotitration (model ET, World Precision Instruments, Inc.).
Drugs. U-46,619 (The Upjohn Co., Kalamazoo, MI) was dissolved in $10 \%$ ethanol and diluted in $0.15 \mathrm{M}$ in $\mathrm{NaCl}$. The final ethanol concentration for infusion never exceeded 0.01\%. SQ-29,548 (Squibb Institute for Medical Research, Summit, NJ) was dissolved in ethanol with equimolar Tris-chloride salt, dried under nitrogen gas, and diluted in $0.15 \mathrm{M} \mathrm{NaCl}$. Furosemide (Hoechst-Roussel Pharmaceuticals, Inc., Somerville, NJ) was dissolved in $0.15 \mathrm{M} \mathrm{NaCl}$.

Statistical methods. Values are reported as mean \pm 1 SEM. Analyses were assessed using an analysis of variance (ANOVA); post-hoc Student's $t$ tests were applied thereafter to parameters or dosages which showed significant effects. Values were taken as statistically significant at $P<0.05$

\section{Results}

The dose-response relationships for changes in GFR, RVR, FVR, and MBP during i.v. infusion of $U-46,619$, compared to its vehicle, are shown in Fig. 1. It is apparent that RVR and GFR were much more sensitive and responsive to U-46,619 than were either FVR or BP. Further data on the dose-response relationships are presented in Table I. The set point for the TGF response (i.e., the values of PSF or SNGFR in the absence of LH perfusion) and the turning point were unaffected by intravenous U-46,619 up to and including 100 $\mathrm{ng} \cdot \mathrm{kg}^{-1} \cdot \mathrm{min}^{-1}$. In contrast, the maximal PSF response (i.e., the change in PSF during changes in the perfusion of the $\mathrm{LH}$ with ATF between 0 and $40 \mathrm{nl} \cdot \mathrm{min}^{-1}$ ) was increased by $90 \%$ during intravenous infusion of U-46,619 at a dose of 10 $\mathrm{ng} \cdot \mathrm{kg}^{-1} \cdot \mathrm{min}^{-1}$. However, neither the GFR nor the RPF was

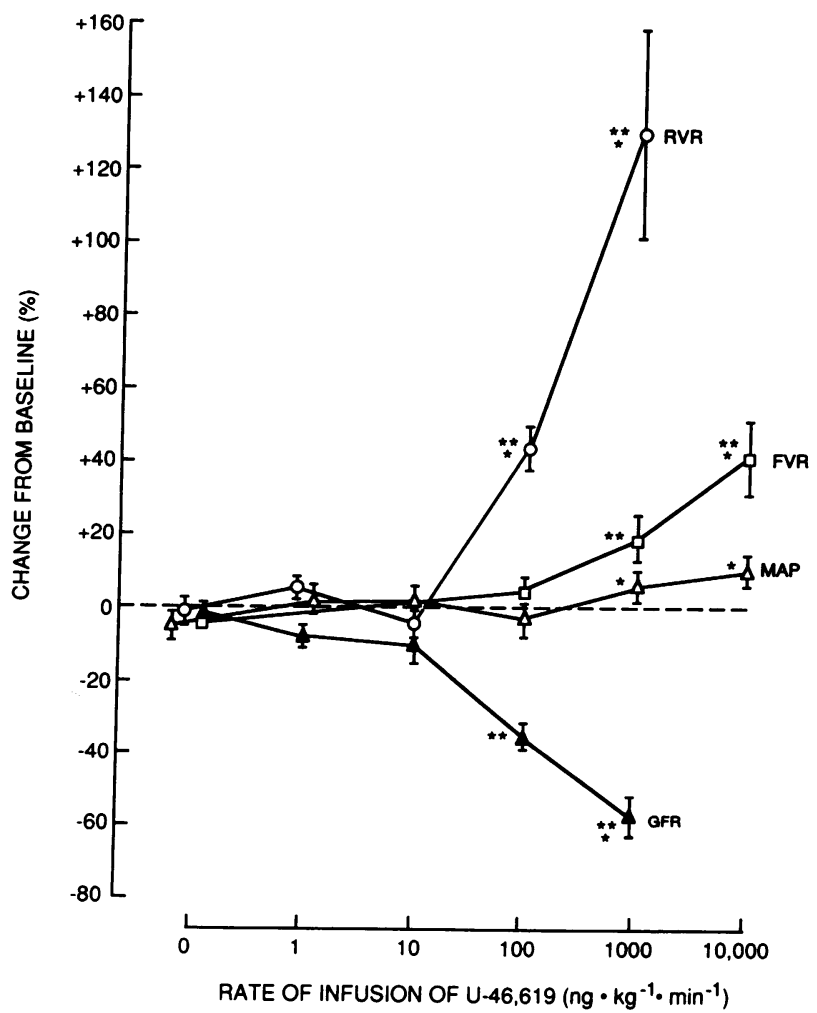

Figure 1. Mean \pm SEM values for percentage changes in glomerular filtration rate, RVR, FVR, and MAP during intravenous infusions of vehicle or $U-46,619$. The numbers of animals studied at each rate of infusion are shown in Table I. Significance of change: ${ }^{*} P<0.05$; ${ }^{* *} P<0.01 ;{ }^{* * *} P<0.001$ 
Table I. GFR, RPF, SNGFR from the Proximal and Distal Nephron, and TGF Parameters: Effects of Intravenous Infusion of Graded Doses of $U-46,619$

\begin{tabular}{|c|c|c|c|c|c|c|c|}
\hline & GFR & RPF & $\begin{array}{l}\text { Proximal } \\
\text { SNGFR }\end{array}$ & $\begin{array}{c}\text { Distal } \\
\text { SNGFR }\end{array}$ & $\begin{array}{l}\text { PSF } \\
\text { set point }\end{array}$ & $\begin{array}{l}\text { Maximal } \\
\text { PFS } \\
\text { response }\end{array}$ & $\begin{array}{c}\text { PSF } \\
\text { turning point }\end{array}$ \\
\hline & \multicolumn{2}{|c|}{$\mathrm{ml} \cdot \mathrm{min}^{-1} \cdot 100 \mathrm{~g}^{-1}$} & \multicolumn{2}{|c|}{$n l \cdot \min ^{-1}$} & \multicolumn{2}{|c|}{$m m H g$} & $n \cdot \cdot \min ^{-1}$ \\
\hline \multicolumn{8}{|l|}{ Group $1(n=10)$ : } \\
\hline Before & $0.78 \pm 0.07$ & $2.81 \pm 0.38$ & & & $33.0 \pm 1.1$ & $10.6 \pm 0.7$ & $19.9 \pm 0.8$ \\
\hline During vehicle & $0.81 \pm 0.09$ & $2.96 \pm 0.38$ & & & $33.9 \pm 1.6$ & $9.7 \pm 0.5$ & $19.4 \pm 0.6$ \\
\hline Change & $+0.03 \pm 0.05$ & $+0.14 \pm 0.14$ & & & $+1.0 \pm 1.1$ & $-0.9 \pm 0.6$ & $-0.5 \pm 0.4$ \\
\hline \multicolumn{8}{|l|}{ Group $2(n=3)$ : } \\
\hline Before & $0.73 \pm 0.07$ & $1.81 \pm 0.15$ & & & $32.3 \pm 2.6$ & $7.7 \pm 0.9$ & $21.3 \pm 0.4$ \\
\hline $\begin{array}{l}\text { During U-46,619 } \\
\left(1 \mathrm{ng} \cdot \mathrm{kg}^{-1} \cdot \min ^{-1}\right)\end{array}$ & $0.83 \pm 0.12$ & $2.28 \pm 0.27$ & & & $32.0 \pm 2.5$ & $6.7 \pm 0.3$ & $22.0 \pm 7.0$ \\
\hline Change & $+0.10 \pm 0.07$ & $+0.47 \pm 0.37$ & & & $-0.3 \pm 0.7$ & $-1.0 \pm 0.6$ & $+0.7 \pm 0.4$ \\
\hline \multicolumn{8}{|l|}{ Group $3(n=9)$ : } \\
\hline Before & $0.86 \pm 0.06$ & $2.85 \pm 0.28$ & $41.1 \pm 2.6$ & $34.0 \pm 1.8$ & $35.8 \pm 1.9$ & $7.8 \pm 0.4$ & $20.1 \pm 0.6$ \\
\hline $\begin{array}{l}\text { During U-46,619 } \\
\left(10 \mathrm{ng} \cdot \mathrm{kg}^{-1} \cdot \mathrm{min}^{-1}\right)\end{array}$ & $0.75 \pm 0.07$ & $2.55 \pm 0.14$ & $\begin{array}{r}39.1 \pm 1.5 \\
(n=6)\end{array}$ & $\begin{array}{l}32.7 \pm 2.5 \\
(n=6)\end{array}$ & $34.5 \pm 1.4$ & $15.9 \pm 2.0$ & $21.2 \pm 1.8$ \\
\hline Change & $-0.11 \pm 0.07$ & $-0.30 \pm 0.24$ & $-2.0 \pm 0.9$ & $-1.3 \pm 1.0$ & $-1.2 \pm 0.9$ & $+7.0 \pm 1.6$ & $+1.2 \pm 1.5$ \\
\hline \multicolumn{8}{|l|}{ Group $4(n=11)$ : } \\
\hline Before & $0.87 \pm 0.08$ & $2.91 \pm 0.17$ & $54.1 \pm 4.8$ & $38.6 \pm 3.9$ & $32.7 \pm 1.3$ & $8.7 \pm 0.6$ & $17.9 \pm 1.0$ \\
\hline $\begin{array}{l}\text { During U-46,619 } \\
\quad\left(100 \mathrm{ng} \cdot \mathrm{kg}^{-1} \cdot \min ^{-1}\right)\end{array}$ & $0.59 \pm 0.07$ & $2.11 \pm 0.17$ & $\begin{array}{r}45.4 \pm 2.1 \\
(n=8)\end{array}$ & $\begin{array}{r}24.1 \pm 2.0 \\
(n=10)\end{array}$ & $32.7 \pm 1.6$ & $18.1 \pm 1.5$ & $17.7 \pm 1.9$ \\
\hline Change & $-0.28 \pm 0.06$ & $-0.80 \pm 0.21$ & $-9.5 \pm 4.2$ & $-14.5 \pm 3.2$ & $0 \pm 0.7$ & $+9.4 \pm 2.0$ & $-0.2 \pm 0.6$ \\
\hline \multicolumn{8}{|l|}{$\begin{array}{c}\text { Effects of U-46,619 } \\
\text { by ANOVA }\end{array}$} \\
\hline $1 \mathrm{ng} \cdot \mathrm{kg}^{-1} \cdot \min ^{-1}$ & NS & NS & & & NS & NS & NS \\
\hline $10 \mathrm{ng} \cdot \mathrm{kg}^{-1} \cdot \mathrm{min}^{-1}$ & NS & NS & NS & NS & NS & $P<0.001$ & NS \\
\hline $100 \mathrm{ng} \cdot \mathrm{kg}^{-1} \cdot \min ^{-1}$ & $P<0.001$ & $P<0.01$ & NS & $P>0.01$ & NS & $P<0.001$ & NS \\
\hline
\end{tabular}

Mean \pm SEM values. $n=$ number of rats studies except for SNGFR where figures in parentheses refer to number of tubules studies. Data for SNGFR was unpaired; in these groups, $P$ values refer to results of unpaired $t$ tests.

changed consistently at $10 \mathrm{ng} \cdot \mathrm{kg}^{-1} \cdot \mathrm{min}^{-1}$ although both were reduced by a similar degree at $100 \mathrm{ng} \cdot \mathrm{kg}^{-1} \cdot \mathrm{min}^{-1}$. This discrepancy between the sensitivity of the single-nephron maximal PSF response to perfusion of the $\mathrm{LH}$ with ATF and the whole-kidney GFR and RPF response might have been due to several factors: distinct effects of $U-46,619$ on $P_{G C}$ and SNGFR, a difference in macula densa response to perfusion with ATF compared to native tubular fluid or a difference between the high rate of $\mathrm{LH}$ perfusion of $40 \mathrm{nl} \cdot \mathrm{min}^{-1}$ used to test the maximal PSF response and the normal rate of flow of tubular fluid into the LH of $10-20 \mathrm{nl} \cdot \min ^{-1}(16)$. Therefore, the role of TGF in control of SNGFR was assessed using a technique which does not depend upon LH perfusion with ATF by comparison of SNGFR values measured at proximal and distal tubules. During the basal period, the mean proximal SNGFR of 29 nephrons was $48.5 \pm 3.4 \mathrm{nl} \cdot \mathrm{min}^{-1}$ which was significantly $(P<0.005)$ higher than the distal SNGFR of 30 nephrons of $35.2 \pm 2.0 \mathrm{nl} \cdot \mathrm{min}^{-1}$. This implies that TGF was actively restraining glomerular filtration in the outer cortical nephrons in the basal state since interruption of delivery of tubular fluid to the macula densa during the proximal measurements was associated with a $38 \%$ increase in SNGFR. There was some unexplained variability in basal values for SNGFR between groups. However, during infusion of $\mathrm{U}-46,619$ at $10 \mathrm{ng} \cdot \mathrm{kg}^{-1} \cdot \mathrm{min}^{-1}$, SNGFR, whether measured from the proximal or distal tubule, was unaltered. During infusion of U-46,619 at 100 $\mathrm{ng} \cdot \mathrm{kg}^{-1} \cdot \mathrm{min}^{-1}$, SNGFR measured from the proximal tubule when TGF was inactive was not changed consistently. However, the SNGFR measured from the distal tubule when TGF was active was significantly reduced by $38 \%$. This corresponds with the $32 \%$ reduction in whole-kidney GFR recorded at this rate of infusion of $U-46,619$ and indicates that, in the presence of an intact macula densa delivery of tubular fluid, GFR and SNGFR have a comparable sensitivity to intravenous infusions of $U-46,619$. In contrast, in the absence of macula densa delivery, neither PSF nor SNGFR were altered consistently by $\mathrm{U}-46,619$ even at $100 \mathrm{ng} \cdot \mathrm{kg}^{-1} \cdot \mathrm{min}^{-1}$.

The dose-response relationship for i.v. infusion of U-46,619 and changes in PSF during graded perfusion of the LH with ATF are shown in Fig. 2. Whereas U-46,619, at rates of infusion of $10 \mathrm{ng} \cdot \mathrm{kg}^{-1} \cdot \mathrm{min}^{-1}$ and above augmented the TGF-induced changes in PSF during LH perfusion with ATF at 20,30 , and $40 \mathrm{nl} \cdot \mathrm{min}^{-1}$, only the higher rates of infusion of $\mathrm{U}-46,619$ of $100 \mathrm{ng} \cdot \mathrm{kg}^{-1} \cdot \mathrm{min}^{-1}$ reduced PSF significantly when the loop was perfused at $10 \mathrm{nl} \cdot \mathrm{min}^{-1}$.

Results of the second protocol are shown in Fig. 3 which depicts the effect on PSF of the addition of graded doses of U-46,619 to ATF perfusing the LH from the late proximal tubule. During zero perfusion of the $\mathrm{LH}$, the PSF for this series averaged $35.9 \pm 0.2 \mathrm{mmHg}$. There were no differences in PSF at 


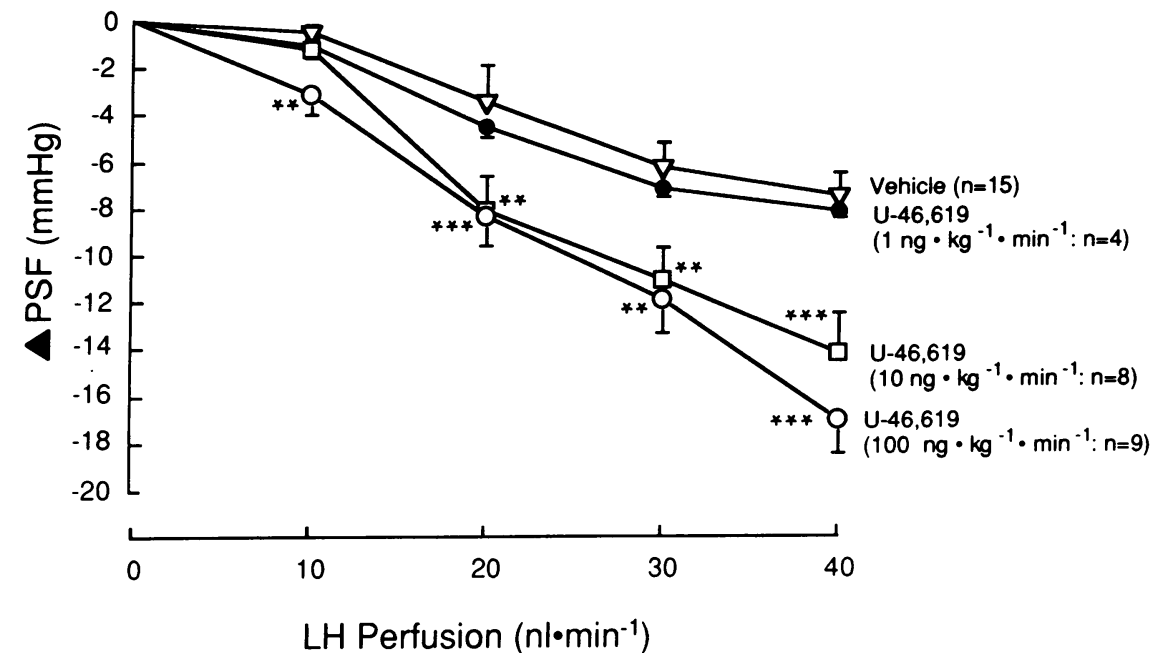

Figure 2. Mean \pm SEM values for changes in PSF during perfusion of the LH with ATF during intravenous infusions of vehicle or U-46,619. Compared to vehicle: ${ }^{* *} P<0.01$; ${ }^{* * *} P<0.001 . n=$ number of rats studied. zero LH perfusion between the five groups. U-46,619 caused a dose-dependent decrease of the maximal PSF response.

In 10 nephrons, changes in SNGFR were compared during LH perfusion with ATF + vehicle and ATF + U-46,619. During zero $\mathrm{LH}$ perfusion, SNGFR was $38.0 \pm 3.7 \mathrm{nl} \cdot \mathrm{min}^{-1}$. During perfusion of the $\mathrm{LH}$ with ATF + vehicle at $40 \mathrm{nl} \cdot \mathrm{min}^{-1}$, SNGFR was reduced by $11.1 \pm 1.5 \mathrm{nl} \cdot \mathrm{min}^{-1}(P<0.001)$. During perfusion of the $\mathrm{LH}$ with ATF $+\mathrm{U}-46,619\left(10^{-6} \mathrm{M}\right)$, it was reduced by $18.2 \pm 3.0 \mathrm{nl} \cdot \mathrm{min}^{-1}$. This was a significant $(P$ $<0.001$ ) potentiation of the response by $64 \%$ which was comparable to the mean potentiation of TGF-induced change in PSF by this dose of luminal U-46,619 of $78 \%$.

For protocol 3, TGF was assessed in seven nephrons from changes in SNGFR during perfusion of the $\mathrm{LH}$ at 0 and 40 $\mathrm{nl} \cdot \mathrm{min}^{-1}$ with ATF. The SNGFR in the absence of perfusion of the $\mathrm{LH}$ was $34.6 \pm 1.5 \mathrm{nl} \cdot \mathrm{min}^{-1}$. During perfusion of the $\mathrm{LH}$ at $40 \mathrm{nl} \cdot \mathrm{min}^{-1}$ with ATF + vehicle, the SNGFR was reduced $(P<0.01)$ to $23.0 \pm 2.3 \mathrm{nl} \cdot \mathrm{min}^{-1}$. The SNGFR was reduced further $(P<0.001)$ with U-46,619 $\left(10^{-6} \mathrm{M}\right)$ 17.2 22.6 $\left.\mathrm{nl} \cdot \mathrm{min}^{-1}\right)$. The SNGFR during addition of U-46,619 $\left(10^{-6} \mathrm{M}\right)$

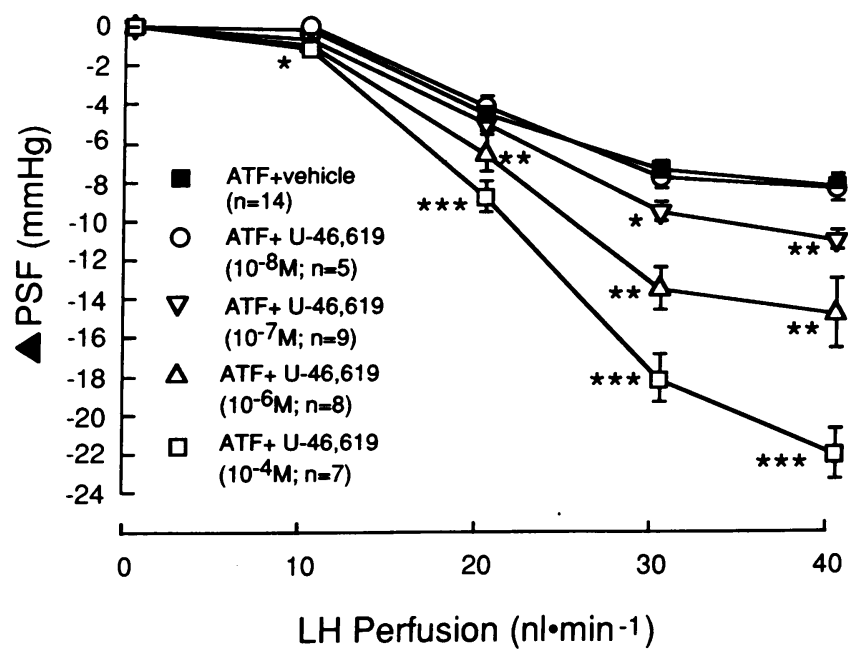

Figure 3. Mean \pm SEM values for changes in PSF during perfusion of the LH with ATF with vehicle or U-46,619. Compared to vehicle: ${ }^{*} P$ $<0.05 ;{ }^{* *} P<0.01 ;{ }^{* * *} P<0.001 . n=$ number of tubules studied. and SQ-29,548 $\left(10^{-4} \mathrm{M}\right)$ to the perfusate was $20.8 \pm 2.4$ $\mathrm{nl} \cdot \mathrm{min}^{-1}$; this was significantly $(P<0.05)$ higher than during perfusion with U-46,619 alone but was also significantly $(P$ $<0.05)$ lower than the value during perfusion with vehicle. This suggests that luminal SQ-29,548 blunted, but did not abolish, the response to U-46,619.

To examine the effects of luminal U-46,619 on macula densa mediated changes in PSF, without potentially confounding effects of alteration in $\mathrm{NaCl}$ transport in the $\mathrm{LH}$ upstream from this segment, TGF-induced changes in PSF were analyzed during retrograde perfusion of the macula densa segment from the early distal tubule at $10 \mathrm{nl} \cdot \mathrm{min}^{-1}$ in four nephrons (protocol 4). The PSF was $36.0 \pm 1.2 \mathrm{mmHg}$ in the absence of perfusion. This was reduced $(P<0.01)$ to $28.0 \pm 1.2 \mathrm{mmHg}$ during perfusion with ATF + vehicle and was reduced further $(P<0.005)$ to $14.1 \pm 1.3 \mathrm{mmHg}$ during perfusion with $\mathrm{ATF}$ $+\mathrm{U}-46,619\left(10^{-6} \mathrm{M}\right)$.

The addition of furosemide $\left(10^{-4} \mathrm{M}\right)$ to orthograde perfusions of the LH with ATF (protocol 5) reduced the maximal PSF response from $8.8 \pm 1.2$ to $2.4 \pm 0.8 \mathrm{mmHg}(P<0.01)$. Fig. 4 shows the effects of luminal furosemide on the dose-response relationship for luminal U-46,619-induced changes in maximal PSF responses. During perfusion with ATF + vehicle, the maximal PSF response was $9.0 \pm 0.9 \mathrm{mmHg}(n=15)$. Compared to this vehicle response, increasing doses of luminal U-46,619 caused a steep potentiation of the maximal PSF responses. This figure also shows that, whereas coperfusion with furosemide $\left(10^{-4} \mathrm{M}\right)$ blunted $68 \%$ of the response to U-46,619 at $10^{-6}$, it did not significantly blunt the response to the highest dose of U-46,619.

Fig. 5 summarizes data from protocol 5 showing the effects on $\mathrm{J}_{\mathrm{C}}$ in the $\mathrm{LH}$ of luminal perfusion with ATF + vehicle compared to ATF + U-46,619 $\left(10^{-6} \mathrm{M}\right)$. Recollection of $\left[{ }^{14} \mathrm{C}\right]-$ inulin in this series averaged $96 \pm 5 \%$ (range $85-104 \%$ ). The $\mathrm{J}_{\mathrm{C}}$ was increased $(P<0.05)$ by $U-46,619$ in all eight tubules. The early distal tubule chloride concentration $\left[E_{\mathrm{Cl}}\right]$ also was reduced $(P<0.05)$ by $U-46,619$.

Additional studies were undertaken to compare the effects of luminal perfusion with U-46,619 added to ATF perfusing the $\mathrm{LH}$ at $40 \mathrm{nl} \cdot \mathrm{min}^{-1}$ (group A; $n=8$ ) with similar perfusions at $20 \mathrm{nl} \cdot \min ^{-1}$ (group B; $n=6$ ) or with furosemide $\left(10^{-4} \mathrm{M}\right.$ ) added to the perfusate delivered at $40 \mathrm{nl} \cdot \mathrm{min}^{-1}$ (group C; 


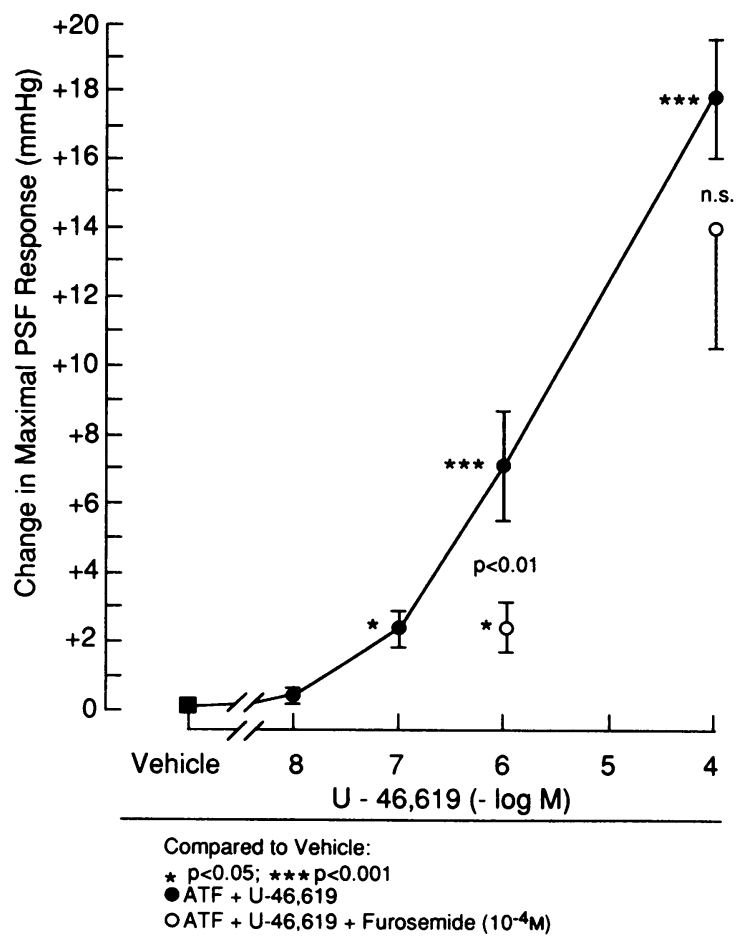

Figure 4. Mean \pm SEM values for change in maximal PSF response (difference between PSF during perfusion of the $\mathrm{LH}$ at $\mathbf{0}$ and at 40 $\mathrm{nl} \cdot \mathrm{min}^{-1}$ ) as a function of the concentration of $\mathrm{U}-46,619$ added to ATF perfusing the LH. Data are shown for perfusates containing ATF + vehicle (a), for ATF + U-46,619 (•) and for ATF

$+\mathrm{U}-46,619+$ furosemide $\left(10^{-4} \mathrm{M} ; \mathrm{O}\right)$. The number of nephrons studied at each concentration of U-46,619 ranged from 5 to 12 . Compared to vehicle: ${ }^{*} P<0.05 ;{ }^{* *} P<0.01 ;{ }^{* * *} P<0.005$.

$n=8$ ). As shown in Fig. 6, the effect of luminal U-46,619 was to increase $\mathrm{J}_{\mathrm{C}}$ and decrease PSF in groups $\mathrm{B}$ and $\mathrm{C}$; these changes in PSF and $\mathrm{J}_{\mathrm{C}}$ with $\mathrm{U}-46,619$ were significant $(P<0.05)$, whereas those during coperfusion with furosemide (group A) were not. There was a unique relationship between $\mathrm{J}_{\mathrm{C}}$ and PSF in these three groups of perfused tubules which
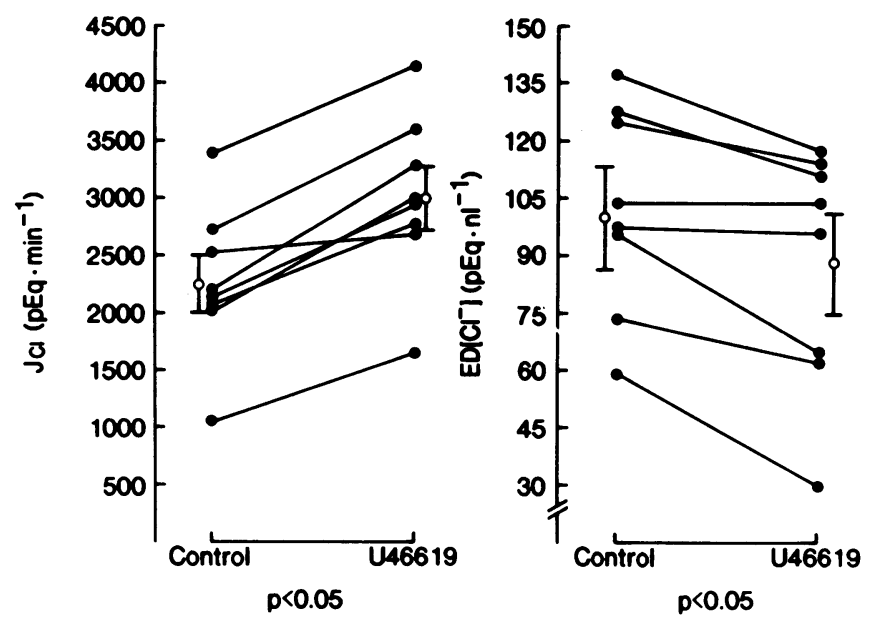

Figure 5. Individual values, and mean $\pm \mathrm{SEM}$, for $\mathrm{J}_{\mathrm{C}}$ (left panel) or $\left[\mathrm{ED}_{\mathrm{CI}}\right]$ (right panel) during perfusion of the LH with ATF (control) or ATF containing U-46,619 $\left(10^{-6} \mathrm{M}\right)$.

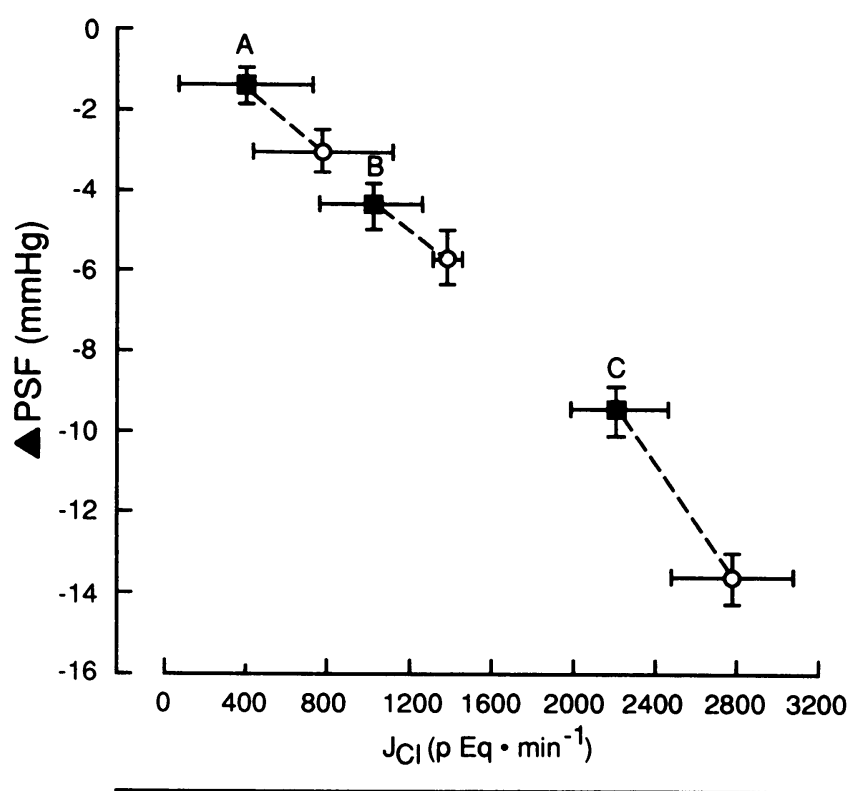
Mean \pm SEM
ATF, O ATF + U-46-619 (10-6M)
A, ATF + furosemide $\left(10^{-4} \mathrm{M}\right)$ at $40 \mathrm{nl} \cdot \mathrm{min}^{-1}$
B, ATF at $20 \mathrm{nl} \cdot \mathrm{min}^{-1}$
C. ATF at $40 \mathrm{nl} \cdot \mathrm{min}^{-1}$

Figure 6. Mean \pm SEM values for changes in PSF as a function of $\mathrm{J}_{\mathrm{Cl}}$ in the LH perfused with ATF containing a vehicle $(\square)$ or U-46,619 $\left(10^{-6}\right.$ $\mathrm{M} ;$ o). During $A$, furosemide $\left(10^{-4} \mathrm{M}\right)$ was added to the $\mathrm{ATF}$, which was perfused at $40 \mathrm{nl} \cdot \min ^{-1}(n=8)$. During $B(n=6)$ and $C(n$ $=8)$, ATF was perfused at 20 and $40 \mathrm{nl} \cdot \mathrm{min}^{-1}$ without furosemide.

persisted whether the $\mathrm{LH}$ perfusate contained vehicle or U-46,619.

The recovery of $\left[{ }^{3} \mathrm{H}\right] \mathrm{U}-46,619$ and $\left[{ }^{14} \mathrm{C}\right]$ inulin added to ATF perfusing the $\mathrm{LH}$ segment at $40 \mathrm{nl} \cdot \mathrm{min}^{-1}$ was studied in nine nephrons of protocol 6 . The fraction of the $\left[{ }^{3} \mathrm{H}\right] \mathrm{U}-46,619$ perfused into the $\mathrm{LH}$ that was reabsorbed by the early distal tubule averaged $88 \pm 5 \%$. Recollection of $\left[{ }^{14} \mathrm{C}\right]$ inulin in this series averaged $95 \pm 7 \%$ (range $85-107 \%$ ).

For the seventh protocol, PTC perfusion with APF alone at $15 \mathrm{nl} \cdot \mathrm{min}^{-1}$ did not modify the TGF response. Additional studies contrasted the effects of PTC perfusions at $15 \mathrm{nl} \cdot \mathrm{min}^{-1}$ with U-46,619 $\left(10^{-6} \mathrm{M}\right)$ added to APF compared to sham perfusions. The PSF was measured in adjacent nephrons during zero perfusion of the $\mathrm{LH}$ and during perfusion with ATF at 40 $\mathrm{nl} \cdot \mathrm{min}^{-1}$. Perfusion with U-46,619 in APF consistently reduced PSF during perfusion of the LH with ATF at 40 $\mathrm{nl} \cdot \mathrm{min}^{-1}$ yet had no effect when the LH was not perfused (Fig. 7).

Because $\left[{ }^{3} \mathrm{H}\right] \mathrm{U}-46,619$ was reabsorbed from the $\mathrm{LH}$, the possibility was considered that U-46,619 perfused into the PTC gained access to the LH perfusion. Accordingly, $\left[{ }^{3} \mathrm{H}\right] \mathrm{U}-46,619$ $\left(40 \mathrm{cpm} \cdot \mathrm{nl}^{-1}\right)$ was added to APF and perfused into the PTC during luminal perfusion of the adjacent LH with ATF at 40 $\mathrm{nl} \cdot \mathrm{min}^{-1}$. The LH perfusate was collected over 3-5 min from the early distal tubule and analyzed for ${ }^{3} \mathrm{H}$ activity. In three studies, no measurable ${ }^{3} \mathrm{H}$ activity was detected. 

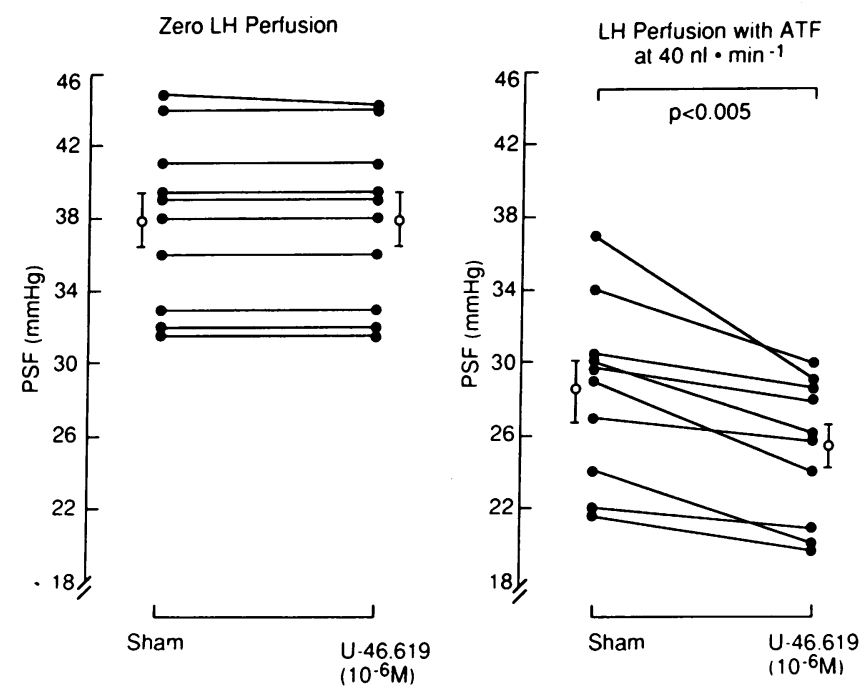

Figure 7. Individual values for single-nephron PSF during perfusion of the LH at 0 (left panel) and $40 \mathrm{nl} \cdot \mathrm{min}^{-1}$ (right panel). The effects of simultaneous perfusion of the PTC with APF to which was added $\mathrm{U}-46,619\left(10^{-6} \mathrm{M}\right)$ are compared to values without PTC perfusion.

\section{Discussion}

The main new findings were the following: U-46,619 caused dose-dependent potentiation of TGF-induced reductions in SNGFR and/or $P_{G C}$ whether given by intravenous infusion or by perfusion of the LH or the PTC. The actions of U-46,619 at the lower doses on PSF or SNGFR were apparent only when macula densa cell function was intact. The i.v. dose that reduced GFR or RPF was 10-100-fold lower than that required to raise FVR or BP. The same dose that reduced distal SNGFR also reduced whole-kidney GFR. Activation of TGF by U-46,619 entailed local actions within the nephron because perfusion of the LH with U-46,619 led to graded reductions in PSF and SNGFR whether given by orthograde perfusion via the LH or by retrograde injection into the macula densa segment. The effect of orthograde perfusion with U-46,619 was blunted by coperfusion with SQ-29,548. Luminal perfusion of the $\mathrm{LH}$ with $\mathrm{U}-46,619$ enhanced $\mathrm{J}_{\mathrm{C}}$ whereas coperfusion with furosemide, at a dose which severely blunted tubular $\mathrm{Cl}$ reabsorption, blunted the effects of low, but not high, doses of luminal U-46,619 on PSF. This suggested that high doses of U-46,619 might exert extraluminal actions. Indeed, it was found that $88 \%$ of $\left.{ }^{3} \mathrm{H}\right] \mathrm{U}-46,619$ was absorbed during one passage through the LH and that infusion of U-46,619 into the PTC reduced PSF during perfusion of the macula densa segment with ATF.

Evidence for involvement of endogenous $\mathrm{TXA}_{2}$ in the modulation of the TGF response was derived from experiments which showed that drugs which inhibit $\mathrm{TXA}_{2}$ synthase or $\mathrm{TXA}_{2} / \mathrm{PGH}_{2}$ receptors blunted the TGF response by $40-60 \%$ $(5,8)$. However, Franco et al. (17) found that local perfusion of the $\mathrm{LH}$ with drugs that block $\mathrm{TXA}_{2}$ synthesis or receptors did not alter the TGF responses. These differences may be explained because endogenous $\mathrm{TXA}_{2}$ was not produced in the perfused LH since this is not a major site of $\mathrm{TXA}_{2}$ synthesis (18). Indeed, the present studies show that a $\mathrm{TXA}_{2} / \mathrm{PGH}_{2}$ receptor antagonist can blunt, but not prevent, U-46,619-in- duced activation of TGF when delivered by local perfusions via the $\mathrm{LH}$. The failure of the luminally-delivered $\mathrm{TXA}_{2} / \mathrm{PGH}_{2}$ receptor antagonist to fully prevent the effects of luminal $\mathrm{U}-46,619$ may be related to different pharmacokinetics of these two drugs. Our data showed that $88 \%$ of $\left[{ }^{3} \mathrm{H}\right] \mathrm{U}-46,619$ perfused via the LH was reabsorbed. Therefore, luminally delivered U-46,619 might reach sites outside the nephron not fully accessible to luminally delivered SQ-29,548.

Potentiation of TGF by U-46,619 is probably not related to renin release inasmuch intravenous infusion of $U-46,619$ into anesthetized rats reduced plasma renin activity (19). Moreover, even at much higher doses, renal hemodynamic responses to $\mathrm{TXA}_{2} / \mathrm{PGH}_{2}$ mimetics are unaffected by angiotensin antagonists (20). Indeed, we found that endogenous release of $\mathrm{TXA}_{2}$ and angiotensin II potentiated TGF by independent means (5).

An apparent paradox was the finding that i.v. infusion of U-46,619 potentiated TGF-induced changes in the maximal PSF response at a dose below that required to reduce wholekidney GFR or RPF (Table I). A likely explanation is that maximal PSF responses were tested by increasing the rate of $\mathrm{LH}$ perfusion to $40 \mathrm{nl} \cdot \mathrm{min}^{-1}$, which greatly exceeds the normal end-proximal flow rate of $10-20 \mathrm{nl} \cdot \mathrm{min}^{-1}$. Indeed, examination of Figure 2 shows that intravenous U-46,619 potentiated TGF at these lower, more physiologically relevant levels of LH perfusion only at doses which corresponded to those which did lower GFR and RPF. The present results raise the possibility that the extreme sensitivity and responsiveness of the renal circulation to $U-46,619$ may depend upon its engagement of the unique renal mechanism of TGF. Thus, with macula densa cell function intact, infusion of $U-46,619$ at 10 $\mathrm{ng} \cdot \mathrm{kg}^{-1} \cdot \mathrm{min}^{-1}$ did not alter either SNGFR measured from the distal tubule or whole-kidney GFR (Table I). However, infusion of $\mathrm{U}-46,619$ at $100 \mathrm{ng} \cdot \mathrm{kg}^{-1} \cdot \mathrm{min}^{-1}$ led to a $38 \%$ reduction in distal SNGFR and a 32\% reduction in whole-kidney GFR. This vasoconstrictive action to these low doses of $U-46,619$ was apparently mediated by the macula densa since there were no consistent changes in either PSF or SNGFR in the absence of perfusion of the macula densa segment. The vasoconstriction was highly selective since a 10-100-fold higher rate of infusion of U-46,619 was required to increase FVR or BP. Further evidence for macula densa-mediated renal vasoconstriction by $\mathrm{TXA}_{2}$ derives from our previous finding that a $\mathrm{TXA}_{2}$ synthase inhibitor increases RBF and GFR and reduces pre- and postglomerular vascular resistances only during hyperchloremia (7) which increases macula densa $\mathrm{Cl}$ delivery and activates TGF (13).

We observed previously that, providing renal perfusion pressure is controlled, drugs which inhibit TXA $\mathbf{A}_{2}$ synthesis or receptors blunt the TGF response only during high rates of $L H$ perfusion (5). This suggests that $\mathrm{TXA}_{2}$ itself may interact with TGF either by augmenting the signal from the macula densa or the afferent arteriolor vasoconstrictor response to this signal. The signal has been related to the reabsorption of solutes, notably $\mathrm{Cl}$, in the macula densa segment $(13,14,21)$. This selectivity of action of $\mathrm{TXA}_{2}$ was confirmed in the present series where the effects of U-46,619 in the lower dose ranges on PSF or SNGFR, whether infused systemically or via the PTC or LH were seen only when macula densa cell function was intact. The present studies provide some support for the hypothesis that one component of the action of U-46,619 on TGF is due to an augmentation of the signal at the macula densa since furosemide, which severely blunted loop $\mathrm{Cl}$ reabsorption, blunted the 
response to low doses of U-46,619 perfused via the LH. Recent evidence indicates the macula densa cells also contain a luminal, furosemide-sensitive $\mathrm{Na}, \mathrm{K}, 2 \mathrm{Cl}$ cotransporter similar to that described in the thick ascending limb of Henle cells (14). The evidence that luminal U-46,619 enhanced loop $\mathrm{J}_{\mathrm{Cl}}$ suggests that $\mathrm{U}-46,619$ can promote TGF by augmenting $\mathrm{Cl}$ reabsorption by the macula densa cells. Previous studies had shown that loop $\mathrm{Cl}$ absorption and TGF responses increase in parallel during perfusion of the $\mathrm{LH}$ between 10 and $30 \mathrm{nl} \cdot \mathrm{min}^{-1}(22)$. However, at higher rates of $\mathrm{Cl}$ delivery and reabsorption, a ceiling is approached beyond which TGF responses are not augmented further (23). Our results showed that U-46,619 reduced PSF across a broad range of $\mathrm{Cl}$ deliveries (Fig. 6). The unique relationship between PSF and $J_{C}$ is consistent with a predominant role for $\mathrm{Cl}$ transport in the regulation of TGF by $\mathrm{U}-46,619$. However, the enhancement of $\mathrm{J}_{\mathrm{C}}$ by luminal U-46,619 reduced the [Cl] of early distal tubule fluid (Fig. 5). Thus, TGF was studied during retrograde perfusion from the early distal tubule to obviate any confounding effects due to alterations in tubular transport upstream from the macula densa. When given more directly near the macula densa, luminal U-46,619 again reduced PSF. This suggests that U-46,619 can alter the signal sensing mechanism at the macula densa. However, if the sole effect of U-46,619 was to augment macula densa cell $\mathrm{Cl}$ transport, one might anticipate that the drug would augment the PSF response to low rates of LH perfusion but would have no further effect when given during perfusion of the $\mathrm{LH}$ with ATF at $40 \mathrm{nl} \cdot \mathrm{min}^{-1}$ when $\mathrm{Cl}$ delivery and reabsorption are maximally effective in stimulating TGF. The data for both intravenous and luminal delivery of U-46,619 (Figs. 2 and 3) suggest that the drug augments PSF during both low and maximal rates of LH perfusion with ATF. This suggests that U-46,619 may also increase the sensitivity of the TGF response. This may be analagous to the recent clarification of the action of angiotensin II on the renal afferent arteriole which requires the presence of a signal generated by the macula densa, perhaps related to adenosine release (24). Furthermore, very high doses of this lipid soluble drug U-46,619 may diffuse from the tubular lumen and vasoconstrict the afferent arteriole independent of macula densa cell function. This is suggested by the finding that coperfusion with furosemide, to block macula densa cell reabsorption, did not significantly attenuate the rise in PSF induced by luminal U-46,619 at the highest dose tested.

The mechanism whereby U-46,619 stimulated $\mathrm{Cl}$ transport in the LH was not established in these studies. U-46,619 promotes net $\mathrm{Cl}$ secretion in the stomach and ileum (25) while infusions of a TXA $\mathrm{TH}_{2}$ synthase inhibitor can increase renal $\mathrm{Cl}$ excretion (8). Studies in isolated tubules from mouse (26) and rabbit (27) thick ascending limbs have shown a $\mathrm{Cl}$ conductance in the basolateral cell membranes. Of interest are the recent findings that the gene for a $\mathrm{TXA}_{2} / \mathrm{PGH}_{2}$ receptor encodes for a protein which functions as a calcium-activated chloride conductance (28). Juxtaglomerular cells contain a major calciumactivated chloride conductance $(14,29)$. Locating the site of action of U-46,619 on the basolateral aspect of the thick ascending limb and macula densa cells may seem inconsistent with the marked effect of luminal U-46,619 on $J_{C l}$ and PSF. However, we found that $\left[{ }^{3} \mathrm{H}\right] \mathrm{U}-46,619$ was very lipid soluble (its olive oil/water partition coefficient at $37^{\circ} \mathrm{C}$ was $66: 34$ ) and that $88 \%$ was lost during a single passage through the LH. Therefore, $U-46,619$ may diffuse from the lumen to the interstitium where it could interact with a basolateral $\mathrm{Cl}$ channel. Indeed, even when given directly into the interstitium by PTC perfusion, $U-46,619$ did not alter $P_{G C}$ unless macula densa function was intact by simultaneous perfusion of the LH with ATF. Therefore, we conclude that one mechanism whereby U-46,619 reduces $P_{G C}$ entails an enhanced generation of the signal that initiates TGF responses at the macula densa cells.

These studies were undertaken with U-46,619 which, although acting on the same receptor at TXA ble and more stable than $\mathrm{TXA}_{2}$, which has a half-life of only some $30 \mathrm{~s}$. The release of $\mathrm{TXB}_{2}$ into urine and renal lymph is increased in a whole-kidney model of TGF (6) whereas TXA synthesis inhibitors reverse the pre- and postglomerular vasoconstriction in this model (7). These observations in the whole animal concur with the more discreet perfusions of the $\mathrm{LH}$ of single nephrons $(5,8)$ and implicate $\mathrm{TXA}_{2}$ in the complex events that relate the tone of the renal resistance vessels to the rate of delivery and reabsorption of $\mathrm{NaCl}$ in the $\mathrm{LH}$ and macula densa.

\section{Acknowledgments}

This work was supported by a grant (RO1-DK 36079) to Dr. Wilcox from the National Institutes of Health. Dr. Wilcox was also supported by the Department of Veterans Affairs Medical Center, Gainesville, Florida. We are grateful to Harold Snellen for expert technical assistance, to Dr. Martin L. Ogletree of the Squibb Institute for Medical Research, Summit, NJ for supply of SQ-29,548, to Garnett Huguley of the Upjohn Company, Kalamazoo, MI for supply of U-46,619, and to Janice M. Dolson for expert secretarial assistance. The tubular fluid chloride analyses were kindly undertaken by Dr. Charles S. Wingo.

\section{References}

1. Briggs, J. P., and F. S. Wright. 1979. Feedback control of glomerular filtration rate: site of the effector mechanism. Am. J. Physiol. 236 (Renal Fluid Electrolyte Physiol. 5):F40-F47.

2. Schnermann, J., and J. Briggs. 1985. Function of the juxtaglomerular apparatus: local control of glomerular hemodynamics. In The Kidney: Physiology and Pathophysiology. D. W. Seldon and G. Giebisch, editors. Raven Press, New York. 669-698.

3. Schnermann, J., H. Weihprecht, and J. P. Briggs. 1990. Inhibition of tubuloglomerular feedback during adenosine receptor blockade. Am. J. Physiol. 258 (Renal Fluid Electrolyte Physiol. 27):F553-F561.

4. Schnermann, J., J. P. Briggs, and P. C. Weber. 1984. Tubuloglomerular feedback, prostaglandins and angiotensin in the autoregulation of glomerular filtration rate. Kidney Int. 25:53-64.

5. Welch, W. J., and C. S. Wilcox. 1990. Feedback responses during sequential inhibition of angiotensin and thromboxane. Am. J. Physiol. 258 (Renal Fluid Electrolyte Physiol. 27):F457-F466.

6. Wilcox, C. S., S. Roddis, W. S. Peart, D. Gordon, and G. P. Lewis. 1985. Intrarenal prostaglandin release: effects of arachidonic acid and hyperchloremia. Kidney Int. 28:43-50.

7. Bullivant, E. M. A., C. S. Wilcox, and W. J. Welch. 1989. Intrarenal vasoconstriction during hyperchloremia: role of thromboxane. Am. J. Physiol. 256 (Renal Fluid Electrolyte Physiol. 25):F152-F157.

8. Welch, W. J., and C. S. Wilcox. 1988. Modulating role for thromboxane in the tubuloglomerular feedback response in the rat. J. Clin. Invest. 81:1843-1849.

9. Bunting, S., L. V. Buchanan, H. H. Holzgrefe, and F. A. Fitzpatrick. 1987. Pharmacology of synthetic thromboxane $\mathrm{A}_{2}$. Adv. Prostaglandins Thromboxanes Leukotriene Res. 17:192-198.

10. Ogletree, M. L., D. N. Harris, R. Greenberg, M. F. Haslonger, and M. Nokone. 1984. Pharmacological actions of SQ-29,548, a novel selective thromboxane antagonist. J. Pharmacol. Exp. Ther. 224:435-441.

11. Kaplan, R., H. S. Aynedjian, N. Bank and P. Schlondorff. 1990. Cholesterol feeding causes renal vasoconstriction via oxidized lipoprotein activation of thromboxane. Kidney Int. 37:371. (Abstr.)

12. Welch, W. J., C. S. Wilcox and W. S. Hubbard. 1989. Single nephron thromboxane concentration: regulation by macula densa and role in tubuloglomerular feedback response. FASEB (Fed. Am. Soc. Exp. Biol.) J. 3:2869. (Abstr.) 
13. Schnermann, J., J. Briggs, and F. S. Wright. 1981. Feedback-mediated reduction of glomerular filtration rate during infusion of hypertonic saline. Kidney Int. 20:462-468.

14. Lapointe, J-Y., D. Bell, A. M. Hurst, and J. Cardinal. 1991. Basolateral ionic permeabilities of macula densa cells. Am. J. Physiol. 260 (Renal Fluid Electrolyte Physiol. 29):F856-F860.

15. Mitchell, K. D., and L. G. Navar. 1987. Superficial nephron responses to peritubular capillary infusions of angiotensin I and II. Am. J. Physiol. 252 (Renal Fluid Electrolyte Physiol. 21):F818-F824.

16. Wilcox, C. S., F. Granges, G. Kirk, D. Gordon, and G. Giebisch. 1984 Effects of saline infusion on titratable acid generation and ammonia secretion. Am. J. Physiol. 247 (Renal Fluid Electrolyte Physiol. 16):F506-F519.

17. Franco, M., P. D. Bell, and L. G. Navar. 1988. Evaluation of prostaglandins as mediators of tubuloglomerular feedback. Am. J. Physiol. 254 (Renal Fluid Electrolyte Physiol. 23):F642-F649.

18. Farmon, N., P. Pradelles, and J. P. Bonvalet. 1987. PGE 2, PGF $_{1 \alpha}, 6$ keto-PGF and $\mathrm{TXB}_{2}$ synthesis along the rabbit nephron. Am. J. Physiol. 252 (Renal Fluid Electrolyte Physiol. 21):F53-F59.

19. Welch, W. J., C. S. Wilcox, and K. R. Dunbar. 1989. Modulation of renin by thromboxane: studies with thromboxane synthesis inhibitor, receptor antagonists, and mimetic. Am. J. Physiol. 257 (Renal Fluid Electrolyte Physiol 26):F554-F560.

20. Gerber, J. G., E. Ellis, J. Hollifield, and A. S. Nies. 1979. Effects of prostaglandin endoperoxide analogue on canine renal function, hemodynamics and renin release. Eur. J. Pharmacol. 53:239-246.

21. Wright, F. S., and J. Schnermann. 1974. Interference with feedback control of glomerular filtration rate by furosemide, triflocin and cyanide. J. Clin. Invest. 53:1695-1708.
22. Blantz, R. C., and K. S. Konnen. 1977. Relation of distal tubular delivery and reabsorptive rate to nephron filtration. Am. J. Physiol. 233 (Renal Fluid Electrolyte Physiol. 2):F315-F324.

23. Briggs, J. P., and J. Schnermann. 1990. The tubuloglomerular feedback mechanism. In Hypertension: Pathophysiology, Diagnosis and Management. J. H. Laragh and B. M. Brenner, editors. Raven Press, New York. 1067-1087.

24. Schnermann, J., H. Weihprecht, J. N. Lorenz, and J. P. Briggs. 1991. The afferent arteriole-the target for macula densa-generated signals. Kidney Int. 38 (Suppl. 32):S74-S77.

25. Bunce, K. T., and C. F. Spraggs. 1990. Prostanoid stimulation of anion secretion in guinea-pig gastric and ileal mucosa is mediated by different receptors. Br. J. Pharmacol. 101:889-895.

26. Friedman, P. A., and T. E. Andreoli. $1982 . \mathrm{CO}_{2}$-stimulated $\mathrm{NaCl}$ absorption in the mouse renal cortical thick ascending limb of Henle: evidence for synchronous $\mathrm{Na}^{+} / \mathrm{H}^{+}$and $\mathrm{Cl} / \mathrm{HCO}_{3}$ exchange in apical plasma membranes. $J$. Gen. Physiol. 80:683-711.

27. Greger, R., H. J., Lang, H. C. Englert, and P. Wangemann, 1987. Blockers of the $\mathrm{Na}^{+}-2 \mathrm{Cl}^{-1}-\mathrm{K}^{+}$carrier and of chloride channels in the thick ascending limb of the loop of Henle. In Diuretics II, Chemistry, Pharmacology and Clinical Application. J. B. Puschett and A. Greenberg, editors. Elsevier Science Publishing Co., Inc., New York. 131-137.

28. Mirata, M., Y. Hayashi, F. Ushikubi, Y. Yokota, R. Kageyama, S. Nakanishi, and S. Narumiya. 1991. Cloning and expression of cDNA for a human thromboxane $A_{2}$ receptor. Nature (Lond.). 349:617-620.

29. Kurtz, A., and R. Penner. 1990. Effects of angiotensin II on intracellular calcium and electrical function of mouse renal juxtaglomerular cells. Kidney Int. 38:S-51-S-54. 